\title{
Laboratory Abnormalities in Polyneuropathy and Electrophysiological Correlations
}

\author{
Alon Abraham, Ari Breiner, Carolina Barnett, Hans D. Katzberg, Mylan Ngo, \\ Leif E. Lovblom, Bruce A. Perkins, Vera Bril
}

\begin{abstract}
To study the frequency of laboratory test abnormalities, and electrophysiological correlations, we performed a retrospective chart review of 226 patients with polyneuropathy. The frequency of laboratory test abnormalities, and correlations with electrophysiological findings were explored. Abnormal glucose handling tests were the most common findings (54\%), followed by paraproteinemia $(21 \%)$ and anemia $(21 \%)$. The frequencies of paraproteinemia and anemia in our cohort were significantly higher than previously reported. In addition, several laboratory abnormalities correlated with electrophysiological findings of median neuropathy at the wrist, expanding current knowledge about the deleterious effects of various metabolic and hematologic derangements at this site.
\end{abstract}

RÉSUMÉ: Résultats anormaux à des tests de laboratoire dans le cas de la polyneuropathie et corrélations électro-physiologiques. Afin de comprendre la fréquence de résultats anormaux à des tests de laboratoire, nous avons mené une étude rétrospective des dossiers de 226 patients atteints de polyneuropathie. Nous avons à cet égard exploré les corrélations existant entre ces résultats anormaux et des observations de nature électro-physiologique. Des résultats anormaux à des tests de tolérance au glucose se sont révélés une des observations les plus courantes (54\%); on a ensuite obtenu des résultats anormaux à des tests pour la paraprotéinémie $(21 \%)$ et l'anémie $(21 \%)$. Les fréquences de paraprotéinémie et d'anémie dans notre cohorte étaient considérablement plus élevées que ce qui avait été signalé antérieurement dans la littérature. De plus, on a pu établir une corrélation entre de nombreux résultats anormaux à des tests et des observations électro-physiologiques se rapportant, au niveau du poignet, à des cas de neuropathie du nerf médian, ce qui permet d'élargir les connaissances actuelles quant aux effets néfastes de divers désordres métaboliques et hématologiques affectant cette région du corps.

Key words: Polyneuropathy, Laboratory tests, Glucose handling, Paraproteinemia, Anemia

doi:10.1017/cjn.2017.298

Can J Neurol Sci. 2018; 45: 346-349

Polyneuropathy is a common neurological disorder, with an overall prevalence of $2.4 \%$, increasing to $8 \%$ in people older than 55 years. ${ }^{1}$ The diagnosis of polyneuropathy is typically based on a combination of clinical symptoms, signs, and electrophysiological findings. ${ }^{2}$ Laboratory tests are used to screen for specific etiologies of polyneuropathy. Although the highest yield of abnormalities is found when testing blood glucose, serum B12 with metabolites and serum immunoelectrophoresis, broader laboratory testing is commonly performed. Additional testing frequently includes complete blood count (CBC), comprehensive biochemical and endocrine panel (including renal function, liver function, thyroid function, folate), erythrocyte sedimentation rate (ESR), rheumatological and other tests. Many of these laboratory tests have low specificity, and an uncertain relationship to the polyneuropathy, so the results must be interpreted in the context of other clinical information. ${ }^{3}$

In this study, we aimed to determine the frequency of laboratory abnormalities found when screening polyneuropathy patients with a broad battery of tests, and to explore their association with electrophysiological findings.

We performed a retrospective chart review of patients diagnosed with polyneuropathy, attending the Prosserman Family
Neuromuscular clinic at the University Health Network, from January 2013 to September 2015. The Research Ethics Board of the University Health Network approved the current study protocol, and waived informed consent.

Inclusion criteria included a diagnosis of polyneuropathy in symptomatic patients who had confirmation by electrophysiological findings, and performed laboratory tests in order to screen for specific etiologies.

Nerve conduction studies were performed using the Sierra Wave instrument (Cadwell Laboratories Inc., Kennewick, Washington), according to the standards of the Canadian Society of Clinical Neurophysiology and the American Association of Neuromuscular and Electrodiagnostic Medicine. For the purposes

From the Department of Medicine, Ellen and Martin Prosserman Centre for Neuromuscular Diseases, Division of Neurology, University Health Network, University of Toronto, Toronto, Canada (AA, AB, CB, HDK, MN, VB); Department of Medicine, Division of Endocrinology and Metabolism, Sinai Health System and Lunenfeld Tanenbaum Research Institute, University of Toronto, Toronto, Canada (LEL, BAP).

Received May 30, 2017. Final Revisions Submitted October 18, 2017. Date of ACCEPTANCE OCTOBER 18, 2017.

Correspondence to: Alon Abraham, Toronto General Hospital, 200 Elizabeth Street, Room 5 EB 309, Toronto, Ontario, Canada M5G 2C4. Email: alonabmail@gmail.com 
of this study, at least one abnormal electrophysiological parameter in the lower limb was required for inclusion. Vibration perception thresholds (VPT) were determined using a Neurothesiometer (Horwell Scientific, London, UK) by the method of limits.

Routine laboratory tests consisted of an extended chemistry panel, including fasting glucose, 2-hour glucose tolerance test (75 g), hemoglobin A1c (HbA1c), renal and liver function, creatine kinase $(\mathrm{CK})$, angiotensin-converting enzyme (ACE), uric acid (UA), CBC, ESR, antinuclear antibodies (ANA), rheumatoid factor, C3, C4, antineutrophil cytoplasmic antibodies, vitamin $\mathrm{B} 12$, folate, thyroid-stimulating hormone (TSH), serum protein immunoelectrophoresis, and anti-GM1 ganglioside antibodies. These tests were performed as part of routine testing, even in patients with an apparent diagnosis, in order to rule out alternative diagnoses or contributing factors.

Statistical analysis was performed using SAS version 9.2 (SAS Institute, Cary, North Carolina), and Prism 6 (GraphPad Software, La Jolla, California). Correlations of laboratory test finding and electrophysiological results were explored using point-biserial correlation coefficients, considering electrophysiological data as continuous variables, and the presence or absence of abnormal laboratory tests, as dichotomous variables.

The total cohort included 226 patients with a mean age was $61 \pm 14$ years, comprising $29 \%$ females. The most common etiology for polyneuropathy was diabetes mellitus in $33 \%$, followed by idiopathic in 19\%, prediabetes in 14\%, and chronic inflammatory demyelinating polyneuropathy in $13 \%$. Their electrophysiological parameters are presented in Table 1.

Abnormal laboratory test results were found in $91 \%$, with an average of 2.3 abnormal test results per patient (Table 2). Abnormal glucose handling tests were the most common (54\%), followed by paraproteinemia $(21 \%)$ and anemia $(21 \%)$. The most common paraprotein was IgG $\kappa$ (Table S1), and the frequency of paraproteinemia increased with age. There were no differences in the frequency of laboratory test abnormalities between patients with and without DSP, except higher frequency of glucose handling tests in those with DSP, and high UA levels of $29 \%$ in those with diabetic sensorimotor polyneuropathy (DSP), compared with $13 \%$ in those without DSP $(p=0.03$ ) (data not shown).

Impaired glucose tolerance, paraproteinemia, low hemoglobin, elevated UA levels and ESR, associated weakly with electrophysiological indices of median neuropathy at the wrist, and elevated VPT at the fingers. None of the laboratory abnormalities were associated with sural nerve amplitudes or conduction velocities. Low hemoglobin and elevated UA levels correlated weakly with higher VPT at the toes (Table S2).

Our study found that laboratory test abnormalities were present in the majority of patients, with at least one abnormality found in $91 \%$ of patients after a broad screening test panel. Glucose dysregulation was the most frequent abnormality as expected, since diabetes is the most common cause of polyneuropathy. ${ }^{4}$ We found a higher than expected frequency of paraproteinemia when compared with previous studies in patients with polyneuropathy, and compared with the normal population of a similar age. ${ }^{5,6}$ However, IgG $\kappa$ was the most common, similar to its distribution in the general population, and the frequency increased with age, as in the general population. ${ }^{6}$ The high prevalence of gammopathy suggests that inflammatory changes might be present in many patients with polyneuropathy. The reduced hemoglobin levels in $21 \%$ of patients were generally
Table 1: Electrophysiological findings and vibration perception thresholds (VPT) in 226 patients with polyneuropathy

\begin{tabular}{|c|c|c|}
\hline & Total cohort & Normal cut-off values \\
\hline \multicolumn{3}{|l|}{ Median sensory } \\
\hline Amplitude $(\mu \mathrm{V})$ & $27.3 \pm 25.9$ & $>15$ \\
\hline Velocity $(\mathrm{m} / \mathrm{s})$ & $49.1 \pm 9$ & $>50$ \\
\hline \multicolumn{3}{|l|}{ Median motor } \\
\hline Distal latency (ms) & $4.3 \pm 1.6$ & $<4$ \\
\hline Amplitude (mV) & $7.5 \pm 3.4$ & $>5$ \\
\hline Velocity $(\mathrm{m} / \mathrm{s})$ & $49.8 \pm 7$ & $>50$ \\
\hline \multicolumn{3}{|l|}{ Sural } \\
\hline Amplitude $(\mu \mathrm{V})$ & $2.6 \pm 3.2$ & $>6$ \\
\hline Velocity $(\mathrm{m} / \mathrm{s})$ & $40.5 \pm 4.6$ & $>40$ \\
\hline \multicolumn{3}{|l|}{ Peroneal } \\
\hline Distal latency (ms) & $5.4 \pm 1.6$ & $<4.5$ \\
\hline Amplitude (mV) & $1.9 \pm 1.9$ & $>2$ \\
\hline Velocity $(\mathrm{m} / \mathrm{s})$ & $37.3 \pm 6.3$ & $>40$ \\
\hline \multicolumn{3}{|l|}{ VPT } \\
\hline Finger (V) & $5.3 \pm 2.7$ & $<5$ \\
\hline Toe $(\mathrm{V})$ & $26.3 \pm 12.4$ & $<15$ \\
\hline
\end{tabular}

Data are shown as means \pm SD.

$\mu \mathrm{V}=$ microvolts $; \mathrm{m} / \mathrm{s}=$ meters per second; $\mathrm{ms}=$ milliseconds; $\mathrm{mV}=$ millivolts; $\mathrm{V}=$ volts.

mild, and mostly normocytic. Although anemia is known to be a common accompaniment to diabetes, ${ }^{7}$ and was found in $26 \%$ of patients with diabetes in our cohort, a high frequency of $17 \%$ was found also in those without diabetes, compared with an expected frequency of $10 \%$ in the general population. ${ }^{8}$ This may represent anemia of chronic disease, although polyneuropathy is not thought to have systemic impact leading to anemia. Another interesting finding was the presence of high UA levels in $19 \%$ of all patients, most commonly in association with the presence of diabetes, consistent with previous literature. ${ }^{9}$

Elevated CK levels were common, demonstrated in $15 \%$ of patients. Although elevated $\mathrm{CK}$ is an indicator of skeletal muscle disease, this finding is by no means specific, and can be demonstrated in neurogenic disorders as well, including polyneuropathies, most likely as a result of axonal loss and denervation leading to impaired muscle membrane integrity.

The frequencies of other laboratory abnormalities, such as elevated creatinine, AST, ALT, TSH, ESR, ANA and ACE were similar to their frequencies in the general population. The yield of routine folate testing was found to be extremely low, similar to previous reports. It should be noted that when ordering multiple independent laboratory tests in a healthy person, there is a chance that one in 20 of the results will be abnormal by random chance alone, as the reference range of a laboratory value is set arbitrarily based on the $95 \%$ confidence interval, meaning that by definition, $5 \%$ of normal individuals may have abnormal values. It was therefore predicted, that most patients in our cohort would have at least one abnormal finding, as 25 different laboratory tests were explored in each patient, but the frequency of abnormalities 
Table 2: Abnormal laboratory tests results in 226 patients with polyneuropathy

\begin{tabular}{|c|c|c|c|c|}
\hline & $\begin{array}{l}\text { Whole } \\
\text { cohort }\end{array}$ & Mean \pm SD & Range & $\begin{array}{c}\text { Normal } \\
\text { values }\end{array}$ \\
\hline Abnormal results & $91 \%$ & NA & NA & NA \\
\hline Average per patient & 2.3 & NA & NA & NA \\
\hline $\mathrm{HbAlc} \uparrow(\%)$ & $40 \%$ & $7.5 \pm 1.9$ & $5.6-15$ & $4-5.6$ \\
\hline IGT $\uparrow(\mathrm{mmol} / \mathrm{L})$ & $32 \%$ & $11.1 \pm 4.7$ & $5.7-30.1$ & $<5.5$ \\
\hline Glucose $\uparrow(\mathrm{mmol} / \mathrm{L})$ & $23 \%$ & $8.4 \pm 3$ & $6.1-20.5$ & $3.6-6$ \\
\hline Glucose dysregulation & $54 \%$ & NA & NA & NA \\
\hline Paraproteins & $21 \%$ & \multicolumn{2}{|c|}{$*$} & Negative \\
\hline Hemoglobin $\downarrow$ (g/L) & $21 \%$ & $118 \pm 13$ & $83-137$ & $\begin{array}{l}\text { F: } 123-153 \\
\text { M: } 140-175\end{array}$ \\
\hline Uric acid $\uparrow(\mu \mathrm{mol} / \mathrm{L})$ & $19 \%$ & $511 \pm 138$ & $381-1008$ & $\begin{array}{l}\text { F: } 143-357 \\
\text { M: } 202-357\end{array}$ \\
\hline $\mathrm{CK} \uparrow(\mathrm{U} / \mathrm{L})$ & $15 \%$ & $443 \pm 236$ & $213-1288$ & $\begin{array}{c}\text { F: }<165 \\
\text { M: } 40-280\end{array}$ \\
\hline $\mathrm{ESR} \uparrow(\mathrm{mm} / \mathrm{hour})$ & $12 \%$ & $46 \pm 15$ & $21-71$ & $<20$ \\
\hline ANA $\uparrow$ (titer) & $10 \%$ & $1: 144$ & 1:40-1:640 & $<1: 40$ \\
\hline Creatinine $\uparrow(\mu \mathrm{mol} / \mathrm{L})$ & $9 \%$ & $133 \pm 21$ & $105-178$ & $50-90$ \\
\hline $\mathrm{ALT} \uparrow(\mathrm{IU} / \mathrm{L})$ & $9 \%$ & $69 \pm 23$ & $44-114$ & $7-35$ \\
\hline $\mathrm{B} 12 \downarrow(\mathrm{pmol} / \mathrm{L})$ & $8 \%$ & $156 \pm 23$ & 106-185 & $>198$ \\
\hline $\mathrm{AST} \uparrow(\mathrm{IU} / \mathrm{L})$ & $7 \%$ & $54 \pm 24$ & $36-123$ & 6-34 \\
\hline $\mathrm{RF} \uparrow(\mathrm{Ku} / \mathrm{L})$ & $6 \%$ & $29 \pm 20$ & $11-86$ & $<10$ \\
\hline $\mathrm{C} 4 \downarrow(\mathrm{g} / \mathrm{L})$ & $6 \%$ & $0.13 \pm 0.03$ & $0.06-0.15$ & $0.16-0.52$ \\
\hline Anti-GM1 $\uparrow(\%)$ & $5 \%$ & $43 \pm 13$ & $30-73$ & $<30$ \\
\hline $\mathrm{TSH} \uparrow(\mathrm{mU} / \mathrm{L})$ & $5 \%$ & $5.7 \pm 1.4$ & $4.1-8.4$ & $0.4-4$ \\
\hline $\mathrm{ACE} \uparrow(\mathrm{U} / \mathrm{L})$ & $4 \%$ & $76 \pm 14$ & $60-98$ & $8-53$ \\
\hline ANCA $\uparrow$ & $4 \%$ & NA & NA & $<0.2$ \\
\hline $\mathrm{C} 3 \uparrow(\mathrm{g} / \mathrm{L})$ & $3 \%$ & $1.78 \pm 0.05$ & $1.73-1.87$ & $0.80-1.70$ \\
\hline $\mathrm{C} 3 \downarrow(\mathrm{g} / \mathrm{L})$ & $2 \%$ & $0.6 \pm 0.1$ & $0.38-0.76$ & $0.80-1.70$ \\
\hline $\mathrm{C} 4 \uparrow(\mathrm{g} / \mathrm{L})$ & $2 \%$ & $0.53 \pm 0.01$ & $0.52-0.55$ & $0.16-0.52$ \\
\hline $\mathrm{TSH} \downarrow(\mathrm{mU} / \mathrm{L})$ & $2 \%$ & $0.09 \pm 0.05$ & 0.09 & $0.4-4$ \\
\hline Uric acid $\downarrow(\mu \mathrm{mol} / \mathrm{L})$ & $2 \%$ & $161 \pm 20$ & $139-190$ & $\begin{array}{l}\text { F: } 143-357 \\
\text { M: } 202-357\end{array}$ \\
\hline Folate $\downarrow$ (nmol/L) & $0 \%$ & NA & NA & $>10.3$ \\
\hline
\end{tabular}

Data are shown as frequencies, means $\pm \mathrm{SD}$, or ranges.

$\mathrm{HbA} 1 \mathrm{c}=$ hemoglobin A1c; IGT = impaired glucose tolerance; glucose dysregulation $=$ abnormal glucose or $\mathrm{HbA1}$; $\mathrm{CK}=$ creatine kinase; $\mathrm{ESR}=$ erythrocyte sedimentation rate; $\mathrm{ANA}=$ antinuclear antibodies; $\mathrm{ALT}=$ alanine transaminase; $\mathrm{AST}=$ aspartate transaminase; $\mathrm{RF}=$ rheumatoid factor; $\mathrm{TSH}=$ thyroid-stimulating hormone; $\mathrm{ACE}=$ angiotensin-converting enzyme; ANCA = antineutrophil cytoplasmic antibodies.

*Additional details can be found in Table 1S.

remains higher than expected in the normal population, even allowing for this statistical consideration.

Several laboratory abnormalities, including impaired glucose tolerance, paraproteinemia, low hemoglobin, elevated UA levels and high ESR, correlated with median neuropathy at the wrist, but not with sural nerve amplitude or conduction velocity. Although median neuropathy at the wrist might reflect a more severe neuropathy, the current study results suggest a preferential susceptibility of the median nerve at this location, to various hematological, biochemical, metabolic and immunological influences. This association of median neuropathy at the wrist has been described previously with paraproteinemia, diabetes, hypothyroidism and acromegaly. Interestingly, within the battery of glucose handling tests, only impaired glucose tolerance was found to correlate with median neuropathy at the wrist, which might underscore its importance in the evolution of polyneuropathy. Changes in hemoglobin, UA or ESR, have not been described in association with median neuropathy at the wrist previously.

Our study has several limitations. Although we explored a relatively extensive panel of laboratory tests, others were not done routinely. In addition, we did not evaluate associations of electrophysiological parameters with less frequent laboratory abnormalities $(<10 \%)$, due to statistical limitations of low numbers. We did not evaluate patients with and without clinical carpal tunnel syndrome, and therefore could not correlate laboratory tests abnormalities with clinical findings, although the presence of clinical carpal tunnel syndrome is not associated with electrophysiological findings in diabetic polyneuropathy. ${ }^{10}$ In addition, a referral bias exists, as our clinic is a tertiary center, and this may lead to misrepresentation of the frequency of different polyneuropathies. However, the most common etiologies in our cohort were DSP and idiopathic neuropathy, similar to their distribution in a community setting. Another limitation is the exclusion of patients with isolated small fiber neuropathies or mononeuropathy, and therefore we are unable to draw conclusions about these peripheral neuropathies. Finally, we did not compare laboratory test findings to a control group comprised of normal subjects, or patients with various other neuromuscular disorders, and therefore cannot address their frequencies in these groups.

In conclusion, most patients with polyneuropathy have some abnormality on laboratory testing, mostly glucose dysregulation, and the frequencies of paraproteinemia and anemia in our cohort were considerably higher than previously reported. Median neuropathy at the wrist was found to be associated with metabolic and hematologic derangements not previously described, and these findings should be confirmed and further explored in prospective studies.

\section{Disclosures}

AA, HDK, MN, LEL and VB have nothing to disclose. AB reports grants from Grifols Inc., other from Pfizer, outside the submitted work. CB reports grants from Octapharma, personal fees from CSL, outside the submitted work. BAP reports grants from NIH and JDRF, and speaker honoraria from Medtronic, Johnson \& Johnson, Roche, GlaxoSmithKline Canada, Novo Nordisk, and Sanofi; he has received research grant support from Medtronic and Boehringer Ingelheim; and serves as a consultant for NeuroMetrix, during the conduct of the study.

\section{Statement of Authorships}

AA, LEL: study concept and design, analysis and interpretation of data; $\mathrm{AB}, \mathrm{MN}, \mathrm{CB}$ : acquisition of data, analysis and interpretation of data; HDK: study concept and design, acquisition of data; BAP: study concept and design, study supervision; VB: study 
concept and design, analysis and interpretation of data, study supervision, critical revision of manuscript for intellectual content.

\section{Supplementary Material}

To view supplementary material for this article, please visit https://doi.org/10.1017/cjn.2017.298

\section{REFERENCES}

1. Martyn CN, Hughes RA. Epidemiology of peripheral neuropathy. J Neurol Neurosurg Psychiatr. 1997;62:310-8.

2. England JD, Gronseth GS, Franklin G, et al. Distal symmetric polyneuropathy: a definition for clinical research: report of the American Academy of Neurology, the American Association of Electrodiagnostic Medicine, and the American Academy of Physical Medicine and Rehabilitation. Neurology. 2005: 199-207.

3. England JD, Gronseth GS, Franklin G, et al. Practice parameter: evaluation of distal symmetric polyneuropathy: role of laboratory and genetic testing (an evidence-based review). Report of the American Academy of Neurology, American Association of
Neuromuscular and Electrodiagnostic Medicine, and American Academy of Physical Medicine and Rehabilitation. Neurology. 2009:185-92.

4. Visser NA, Notermans NC, Linssen RSN, van den Berg LH, Vrancken AFJE. Incidence of polyneuropathy in Utrecht, the Netherlands. Neurology. 2015;84:259-64.

5. Saleun JP, Vicariot M, Deroff P, Morin JF. Monoclonal gammopathies in the adult population of Finistère, France. J Clin Pathol. 1982;35:63-8.

6. Kyle RA, Therneau TM, Rajkumar SV, et al. Prevalence of monoclonal gammopathy of undetermined significance. N Engl J Med. 2006;354:1362-9.

7. Thomas MC, MacIsaac RJ, Tsalamandris C, Power D, Jerums G. Unrecognized anemia in patients with diabetes: a crosssectional survey. Diabetes Care. 2003;26:1164-9.

8. Patel KV. Epidemiology of anemia in older adults. Semin Hematol. 2008;45:210-7.

9. Papanas N, Katsiki N, Papatheodorou K, et al. Peripheral neuropathy is associated with increased serum levels of uric acid in type 2 diabetes mellitus. Angiology. 2011;62:291-5.

10. Perkins BA, Olaleye D, Bril V. Carpal tunnel syndrome in patients with diabetic polyneuropathy. Diabetes Care. 2002; 25:565-9. 